Correspondence

Alexander Steinbüchel

steinbu@uni-muenster.de

Received 28 June 2006

Revised 19 October 2006

Accepted 23 October 2006

\section{Heat-shock protein HspA mimics the function of phasins sensu stricto in recombinant strains of Escherichia coli accumulating polythioesters or polyhydroxyalkanoates}

\author{
Nicole Tessmer, ${ }^{1}$ Simone König, ${ }^{2}$ Ursula Malkus, ${ }^{3}$ Rudolf Reichelt, ${ }^{3}$ \\ Markus Pötter ${ }^{1}$ and Alexander Steinbüchel ${ }^{1}$ \\ ${ }^{1}$ Institut für Molekulare Mikrobiologie und Biotechnologie, Westfälische Wilhelms-Universität \\ Münster, Corrensstraße 3, D-48149 Münster, Germany \\ ${ }^{2}$ Integrierte Funktionelle Genomik, Westfälische Wilhelms-Universität Münster, Röntgenstraße \\ 21, D-48149 Münster, Germany \\ ${ }^{3}$ Institut für Medizinische Physik und Biophysik, Universitätsklinikum, Westfälische \\ Wilhelms-Universität Münster, Robert-Koch-Straße 31, D-48149 Münster, Germany
}

\begin{abstract}
Polyhydroxyalkanoic acids (PHAs) are synthesized by unspecific PHA synthases and deposited as energy and carbon storage granules in the cytoplasm of many prokaryotes. The number and size of the granules depend on the presence of phasins which are amphiphilic structural proteins occurring at the granule surface. Recently, it was shown that polythioesters (PTEs) are also synthesized by PHA synthases. To increase the yield of these polymers, the role of recombinant phasins was analysed in an artificial PHA-producing Escherichia coli strain. Overexpressed PhaP1 from Ralstonia eutropha $\mathrm{H} 16$ affected poly(3-mercaptopropionate) [poly(3MP)] and poly(3-hydroxybutyrate) [poly(3HB)] accumulation in recombinant $E$. coli, which expressed the non-natural BPEC pathway consisting of butyrate kinase and phosphotransbutyrylase from Clostridium acetobutylicum and PHA synthase from Thiococcus pfennigii. For this, BPEC-carrying E. coli with and without phaP1 was cultivated in presence of glucose as carbon source for growth plus 3-mercaptopropionate or 3-hydroxybutyrate as precursor substrates for poly(3MP) or poly (3HB) biosynthesis, respectively. In the presence of PhaP1, the recombinant $E$. coli produced about 50 or $68 \%$ more poly(3MP) or poly(3HB), respectively. Therefore, coexpression of PhaP1 alongside the BPEC pathway is important for optimizing strains towards enhanced PHA or PTE production. Furthermore, in the absence of PhaP1, large amounts of the $16 \mathrm{kDa}$ heat-shock protein HspA were synthesized and bound to the granule surface. Unusual small granules occurred in the cells of the recombinant $E$. coli strains. The diameter of the poly(3MP) granules was only $55 \pm 12 \mathrm{~nm}$ or $105 \pm 12 \mathrm{~nm}$, and of the poly(3HB) granules only $56 \pm 10$ or $110 \pm 22 \mathrm{~nm}$ in the presence or absence of PhaP1, respectively. This explains why no single granules capable of accumulating PHAs or PTEs occurred in the recombinant $E$. coli, unlike in PhaP1-negative mutants of $R$. eutropha. Obviously, HspA mimics the phasin, thereby preventing coalescence of granules into one single granule. However, the effect of PhaP1 on granule size and on amounts of accumulated polymers was more severe than that of $\mathrm{HspA}$.
\end{abstract}

\section{INTRODUCTION}

Polythioesters (PTE), consisting of various 3-mercaptoalkanoic acids, were shown to be a new class of biopolymers by Lütke-Eversloh et al. (2001a). PTEs are synthesized by polyhydroxyalkanoate (PHA) synthases, which are the key enzymes for biosynthesis of the polyoxoesters

Abbreviations: 3HB, 3-hydroxybutyric acid; 3MP, 3-mercaptopropionic acid; PHA, polyhydroxyalkanoate; PTE, polythioester. poly(3-hydroxybutyrate) [poly(3HB)] or other PHAs (Taguchi \& Doi, 2004) if bacteria are cultivated in the presence of organic thiochemicals yielding mercaptoacylcoenzyme A thioesters by cell metabolism, thus indicating the low substrate specificity of these enzymes (Steinbüchel \& Valentin, 1995). The Gram-negative bacterium Ralstonia eutropha accumulates copolymers of 3-hydroxybutyrate $(3 \mathrm{HB})$ and 3-mercaptopropionate (3MP), 3-mercaptobutyrate $(3 \mathrm{MB})$ or 3 -mercaptovalerate $(3 \mathrm{MV})$ when the cells are cultivated under conditions permissive for PHA 
biosynthesis in the presence of various thiochemicals (Lütke-Eversloh et al., 2001a, b; Lütke-Eversloh \& Steinbüchel, 2003). A recombinant strain of Escherichia coli expressing the non-natural BPEC pathway, relying on the enzymes butyrate kinase (Buk) and phosphotransbutyrylase (Ptb) from Clostridium acetobutylicum plus a twocomponent PHA synthase (PhaEC) from non-oxygenic photosynthetic bacteria like Allochromatium vinosum or Thiococcus pfennigii (Liu \& Steinbüchel, 2000a, b), synthesized poly (3MP), poly (3MB) or poly (3MV) homopolymers when cultivated in the presence of the respective 3mercaptoalkanoic acids (Lütke-Eversloh et al., 2002a). In addition, PTEs were also synthesized in vitro, employing the Candida antarctica lipase (Iwata et al., 2003; Kato et al., 2005).

PTEs exhibit interesting physical and biological properties. Thermal properties such as the melting point temperature and glass transition temperatures deviate significantly from those of the corresponding polyoxoester analogues (LütkeEversloh et al., 2002a, b; Kawada et al., 2003; Tanaka et al., 2004). For example, the melting point temperature $\left(T_{\mathrm{m}}\right)$ increases from $121{ }^{\circ} \mathrm{C}$ in poly $(3 \mathrm{HB})$ to $170{ }^{\circ} \mathrm{C}$ in poly $(3 \mathrm{MP})$. The PTE homopolymer poly(3MP) has recently become available in sufficient quantities by up-scaling the BPEC process to the $500 \mathrm{l}$ scale and has been used for biodegradation studies (Thakor et al., 2005). Surprisingly, it turned out that poly (3MP) is non-biodegradable (Elbanna et al., 2004; Kim et al., 2005).

Transmission electron microscopic studies of thin sections of cells of the recombinant $E$. coli strain producing poly (3MP) show a large number of unusually small granules (Lütke-Eversloh et al., 2002a) in comparison to granules occurring, for example, in R. eutropha. This was surprising because the PTE biosynthesis pathway was expressed in the absence of a phasin protein. Phasins represent a class of small, amphiphilic structural proteins that bind to the surface of PHA granules and cover most of the surface (Wieczorek et al., 1995). These amphiphilic proteins constitute a boundary layer between the hydrophobic surface of the PHA granules owing to the amorphous hydrophobic polyester molecules and the mostly hydrophilic constituents of the cytoplasm. Thus they stabilize the 'PHA in water dispersion' in the cytoplasm, thereby yielding distinct, non-coalescing granules (Steinbüchel et al., 1995; Pötter \& Steinbüchel, 2005). R. eutropha synthesizes four homologous phasin proteins (PhaP1, PhaP2, PhaP3 and PhaP4) with PhaP1 being the most abundant protein constituting about $3-5 \%(\mathrm{w} / \mathrm{w})$ of the total cell protein if the cells contain large amounts of PHAs (Wieczorek et al., 1995; Pötter et al., 2004). The number and size of PHA granules in cells depend very much on the presence of phasin proteins. In most cells of a phaP1 mutant of $R$. eutropha, only one single large and oval granule (length up to $2 \mu \mathrm{m}$ ) is seen, which occupies almost the entire cytoplasm, whereas wildtype cells accumulate several round granules of medium size $(0.2-0.5 \mu \mathrm{m}$ diam.). Furthermore, $R$. eutropha cells harbouring several copies of the phaP1 gene contain a much larger number of granules of small size. These findings provide evidence for the hypothesis of the 'PHA in water emulsion'-stabilizing effect of phasins.

Since PTE and PHA molecules are not very different with regard to the hydrophobicity of the polymer molecules, the extraordinary small size of PTE granules in recombinant $E$. coli cells is not consistent with the hypothesis mentioned above. It indicates that other proteins could override the function of phasins in E. coli. Therefore, we investigated the proteins associated with PTE granules in recombinant E. coli strains expressing the BPEC pathway in the absence and presence of PhaP1 and of other R. eutropha phasins under conditions permissive for poly(3MP) or poly (3HB) biosynthesis and accumulation.

\section{METHODS}

Bacterial strains and growth conditions. The bacterial strains used in this study are listed in Table 1 . E. coli was cultivated at $37^{\circ} \mathrm{C}$ in $500 \mathrm{ml} \mathrm{M9}$ mineral salts medium (Sambrook et al., 1989) supplemented with $0.01 \%(\mathrm{w} / \mathrm{v})$ yeast extract in 21 Erlenmeyer flasks with baffles on a rotary shaker at 125 r.p.m. As carbon source, $1.0 \%(\mathrm{w} / \mathrm{v})$ glucose was added from a $20 \%(\mathrm{w} / \mathrm{v})$ filter-sterilized stock solution. After 12 h, 3-mercaptopropionic acid (99\%; Acros Organics) or sodium 3-hydroxybutyrate (Sigma-Aldrich Chemie) was added to the medium as the precursor substrate for poly $(3 \mathrm{MP})$ or poly $(3 \mathrm{HB})$ synthesis, respectively, to a concentration of $0.2 \%(\mathrm{v} / \mathrm{v}$ or $\mathrm{w} / \mathrm{v}$, respectively). In addition, $1 \mathrm{mM}$ IPTG was added to induce transcription of phaP1 on pCDFDuet-1. To maintain the plasmids, $75 \mu \mathrm{g}$ ampicillin $\mathrm{ml}^{-1}$ was added to E. coli BL21 (DE3)/pBPP1 and $75 \mu \mathrm{g}$ ampicillin $\mathrm{ml}^{-1}$ plus $50 \mu \mathrm{g}$ streptomycin $\mathrm{ml}^{-1}$ to E. coli BL21 (DE3)/pBPP1 + pCDFDuet-1 : : phaP1.

Cloning of phaP1. For cloning of phaP1 into E. coli, PCR was done by using phaP1_(NcoI_IV) (5'-CCAGCCATGGTCCTCACCCCGGAACAAGTTGC-3') as sense and phaP1(rev)_C_HindIII (5'-GCAGAAGCTTATCAGGCAGCCGTCGTCTTC-3') as reverse primers, thereby introducing an NcoI restriction site in the upstream region and a HindIII restriction site in the downstream region of the gene, respectively. The PCR amplification of DNA was carried out as described by Sambrook et al. (1989), employing Pfx DNA polymerase (Invitrogen) and an Omnigene HBTR3CM DNA thermal cycler (Hybaid). By using the Perfectprep Gel Cleanup Kit (Eppendorf), following the instructions described in the enclosed manual, the 579 bp fragment was purified from an agarose gel. The fragment was then digested with $\mathrm{NcoI}$ and HindIII, and was ligated into NcoIand HindIII-digested pCDFDuet-1 vector DNA (Novagen), yielding pCDFDuet-1 : : phaP1.

Transfer of DNA. Competent E. coli cells were prepared and transformed by the $\mathrm{CaCl}_{2}$ procedure as described by Hanahan (1983).

Analysis of PHAs and PTEs. The polymer contents of the cells were determined upon methanolysis of 5-10 $\mathrm{mg}$ lyophilized cells in the presence of $85 \%(\mathrm{v} / \mathrm{v})$ methanol and $15 \%(\mathrm{v} / \mathrm{v})$ sulfuric acid. The resulting methyl esters of 3-HB and 3-MP were analysed by GC as described by Brandl et al. (1988) and Timm \& Steinbüchel (1990).

Isolation of native PHA and PTE granules. For the examination of granule-associated proteins, poly $(3 \mathrm{HB})$ and poly $(3 \mathrm{MP})$ granules were isolated by a modification of the method of Preusting et al. (1993) from E. coli cells which had been grown in M9 medium. 
Table 1. Bacterial strains and plasmids used in this study

\begin{tabular}{|c|c|c|}
\hline Strain or plasmid & Description & Reference or source \\
\hline \multicolumn{3}{|l|}{ Ralstonia eutropha } \\
\hline H16 & Wild-type & DSM 428 \\
\hline \multicolumn{3}{|l|}{ Escherichia coli } \\
\hline BL21 (DE3) & $\begin{array}{l}\mathrm{F}^{-} \operatorname{ompT} h s d S B\left(\mathrm{r}_{\mathrm{B}}^{-}, \mathrm{m}_{\mathrm{B}}^{-}\right) \\
\text {gal dcm }(\mathrm{DE} 3)\end{array}$ & Novagen \\
\hline \multicolumn{3}{|l|}{ Plasmids } \\
\hline pBPP1 & $\mathrm{Ap}^{\mathrm{r}} b u k^{+} p t b^{+} p h a E C$ & Liu \& Steinbüchel (2000b) \\
\hline pCDFDuet-1 & $\mathrm{Sm}^{\mathrm{r}}$ & Novagen \\
\hline pCDFDuet-1::phaP1 & $\mathrm{Sm}^{\mathrm{r}}$ phaP1 ${ }^{+}$ & This study \\
\hline
\end{tabular}

Samples $(50 \mathrm{ml})$ were withdrawn from the medium after 18, 24, 30 and $36 \mathrm{~h}$ incubation. The cells were harvested by centrifugation $\left(20 \mathrm{~min}, 6000 \mathrm{~g}, 4{ }^{\circ} \mathrm{C}\right.$ ), washed in $100 \mathrm{mM}$ Tris/HCl buffer ( $\mathrm{pH} 8.0$ ) and then suspended in $2 \mathrm{ml} 100 \mathrm{mM}$ Tris/ $\mathrm{HCl}$ buffer $(\mathrm{pH} \mathrm{8.0)}$ ). After a threefold passage through a French press $\left(100 \times 10^{6} \mathrm{~Pa}\right)$, the lysate was loaded on the top of a glycerol gradient. The gradient used for isolation of poly $(3 \mathrm{HB})$ granules was obtained from a discontinuous gradient prepared from $4 \mathrm{ml} 90 \%(\mathrm{v} / \mathrm{v})$ plus $4 \mathrm{ml} 60 \%$ (v/v) glycerol in $100 \mathrm{mM}$ Tris/HCl buffer $(\mathrm{pH} 8.0)$. The gradient for isolation of poly $(3 \mathrm{MP})$ granules was prepared from $3 \mathrm{ml} 90 \%(\mathrm{v} / \mathrm{v})$, $3 \mathrm{ml} 80 \%(\mathrm{v} / \mathrm{v})$ plus $3 \mathrm{ml} 60 \%(\mathrm{v} / \mathrm{v})$ in $100 \mathrm{mM}$ Tris $/ \mathrm{HCl}$ buffer ( $\mathrm{pH}$ 8.0). After centrifugation $\left(1 \mathrm{~h}, 100000 \mathrm{~g}, 4^{\circ} \mathrm{C}\right)$, a granule layer of poly $(3 \mathrm{HB})$ was obtained at about $90 \%(\mathrm{v} / \mathrm{v})$ glycerol and a layer of poly $(3 \mathrm{MP})$ at about $80 \%(\mathrm{v} / \mathrm{v})$ glycerol. The granules were isolated from the gradients and then washed three times with $\mathrm{Tris} / \mathrm{HCl}$ buffer $(\mathrm{pH} 8.0)$ by centrifugation $\left(15 \mathrm{~min}, 16100 \mathrm{~g}, 4{ }^{\circ} \mathrm{C}\right)$. The granules were stored at $-20^{\circ} \mathrm{C}$ for further analyses.

One-dimensional PAGE. Protein samples were resuspended in gel loading buffer $(0.6 \%, \mathrm{w} / \mathrm{v}, \mathrm{SDS} ; 1.25 \%, \mathrm{v} / \mathrm{v}, \beta$-mercaptoethanol; $0.25 \mathrm{mM}$ EDTA; $10 \%$, v/v, glycerol; $0.001 \%$, w/v, bromophenol blue; $12.5 \mathrm{mM}$ Tris/ $\mathrm{HCl}, \mathrm{pH} 6.8$ ) and were separated in $12.5 \%$ (w/v) SDS-polyacrylamide gels as described by Laemmli (1970). The proteins were stained with Coomassie brilliant blue R-250 (Weber \& Osborn, 1969). Samples of crude extracts and of the native isolated granules were examined by this method.

Analysis of granule-associated proteins by MALDI-TOF MS. Spots were excised from the PAGE gels, destained and washed using a slightly modified procedure to that described by Koltzscher et al. (2003). Proteins were tryptically digested in the gel, and peptides were extracted and C18-purified for MALDI-TOF MS. Peptide masses were measured using TofSpec-2E (Waters/Micromass). Database searches were performed with the Mascot engine in-house (Matrix Science) on Swiss-Prot, specifying E. coli proteins.

Electron microscopy studies. To obtain transmission electron micrographs (TEM), cells were fixed with $2.5 \%$ (v/v) glutaraldehyde in $0.1 \mathrm{M}$ PBS ( $\mathrm{pH} 7.3$ ) immediately after they were withdrawn from the cultivation vessels. After three washing steps with $0.1 \mathrm{M}$ PBS each for $20 \mathrm{~min}$, the cells were post-fixed in $1 \%(\mathrm{w} / \mathrm{v})$ osmium tetroxide in 0.1 M PBS ( $\mathrm{pH} \mathrm{7.3)} \mathrm{and} \mathrm{washed} \mathrm{once} \mathrm{with} \mathrm{the} \mathrm{same} \mathrm{PBS}$ for $20 \mathrm{~min}$. Then water was removed by a graded water/ethanol series $(30,50,70,90,96 \%, \mathrm{v} / \mathrm{v}$, ethanol in water and absolute ethanol as final step), each step lasting for about $15 \mathrm{~min}$. The following preparation steps were made according to the specific requirements of the microscopic method used. For thin sectioning, the samples were embedded in SPURR resin (without propylene oxide) (Spurr, 1969). Sections with a thickness of $70-80 \mathrm{~nm}$ were made with an Ultracut apparatus (Leica Mikroskopie und Systeme) using a diamond knife and were then positioned on a 200 mesh copper grid.
Imaging was performed with an H-500 transmission electron microscope (Hitachi) in the bright-field mode at $75 \mathrm{kV}$ acceleration voltage and at room temperature. Photographs were taken on AgfaGevaert 23 D 56 films.

\section{RESULTS AND DISSCUSION}

\section{Construction of plasmids for coexpression of the BPEC pathway and phasin PhaP1}

The major phasin PhaP1 influences the accumulation of poly(3HB) in R. eutropha H16 (Pötter et al., 2004). To analyse the impact of PhaP1 on the accumulation of poly (3MP) in E. coli, we combined the genes encoding the non-natural BPEC pathway with phaP1. Moreover, the BPEC pathway was used to produce poly $(3 \mathrm{HB})$ in the presence and absence of PhaP1. For this, phaP1 was inserted into pCDFDuet-1, as described in Methods, yielding pCDFDuet-1::phaP1 (Fig. 1a). The genes for the BPEC pathway are encoded on the $11.96 \mathrm{kbp}$ vector pBPP1 (Fig. 1b). Because of the compatibility of the two plasmids, they could both be transferred to and maintained in E. coli BL21 (DE3). In addition, E. coli BL21 (DE3) was transformed with pBPP1 only as a negative control.

\section{Influence of PhaP1 on accumulation of poly(3MP) and poly(3HB)}

$R$. eutropha $\mathrm{H} 16$ cells, defective in phaP1, produce less poly(3HB) than the wild-type (Wieczorek et al., 1995) and exhibit a PHA-leaky phenotype. Therefore, coexpression of $\mathrm{PhaP} 1$ in recombinant strains of E. coli capable of accumulating PTEs due to the expression of a PHA biosynthesis pathway might yield greater PTE content in the cells. The effect of phaP1 on poly $(3 \mathrm{HB})$ and poly $(3 \mathrm{MP})$ accumulation in $E$. coli cells expressing the non-natural BPEC pathway has not been investigated yet. To analyse the influence of PhaP1 from $R$. eutropha $\mathrm{H} 16$ on the accumulation of poly $(3 \mathrm{MP})$ and poly $(3 \mathrm{HB})$ in recombinant strains of $E$. coli expressing the non-natural BPEC pathway, E. coli BL21 (DE3)/pBPP1 and E. coli BL21 (DE3)/ pBPP1+pCDFDuet-1::phaP1 were cultivated in M9 medium containing glucose. After $12 \mathrm{~h}$ cultivation, $3 \mathrm{MP}$ or $3 \mathrm{HB}$ was added and served as precursor substrates for 
poly(3MP) or poly(3HB) biosynthesis, respectively. After induction of expression of phaP 1 by adding IPTG after $12 \mathrm{~h}$, the cells were then further cultivated for $24 \mathrm{~h}$. To obtain reliable results, all cultivations were done in duplicate. The growth behaviour of phasin-positive and -negative cultures was similar (Figs 2 and 3 ) and after about $18 \mathrm{~h}$ of cultivation, the cells reached stationary phase. Samples were withdrawn every $6 \mathrm{~h}$ and the poly $(3 \mathrm{HB})$ and poly(3MP) contents of the cells were analysed.

Coexpression of PhaP1 exerted a clear positive effect on poly (3MP) and poly(3HB) accumulation in E. coli BL21 $(\mathrm{DE} 3) / \mathrm{pBPP} 1+\mathrm{pCDFDuet}-1:$ phaP1 when the cells were cultivated in the presence of $3 \mathrm{MP}$ or $3 \mathrm{HB}$, respectively. It should be noted that the cells only accumulated the respective homopolymer as shown in previous studies (Lütke-Eversloh et al., 2002a; Liu \& Steinbüchel, 2000b). In
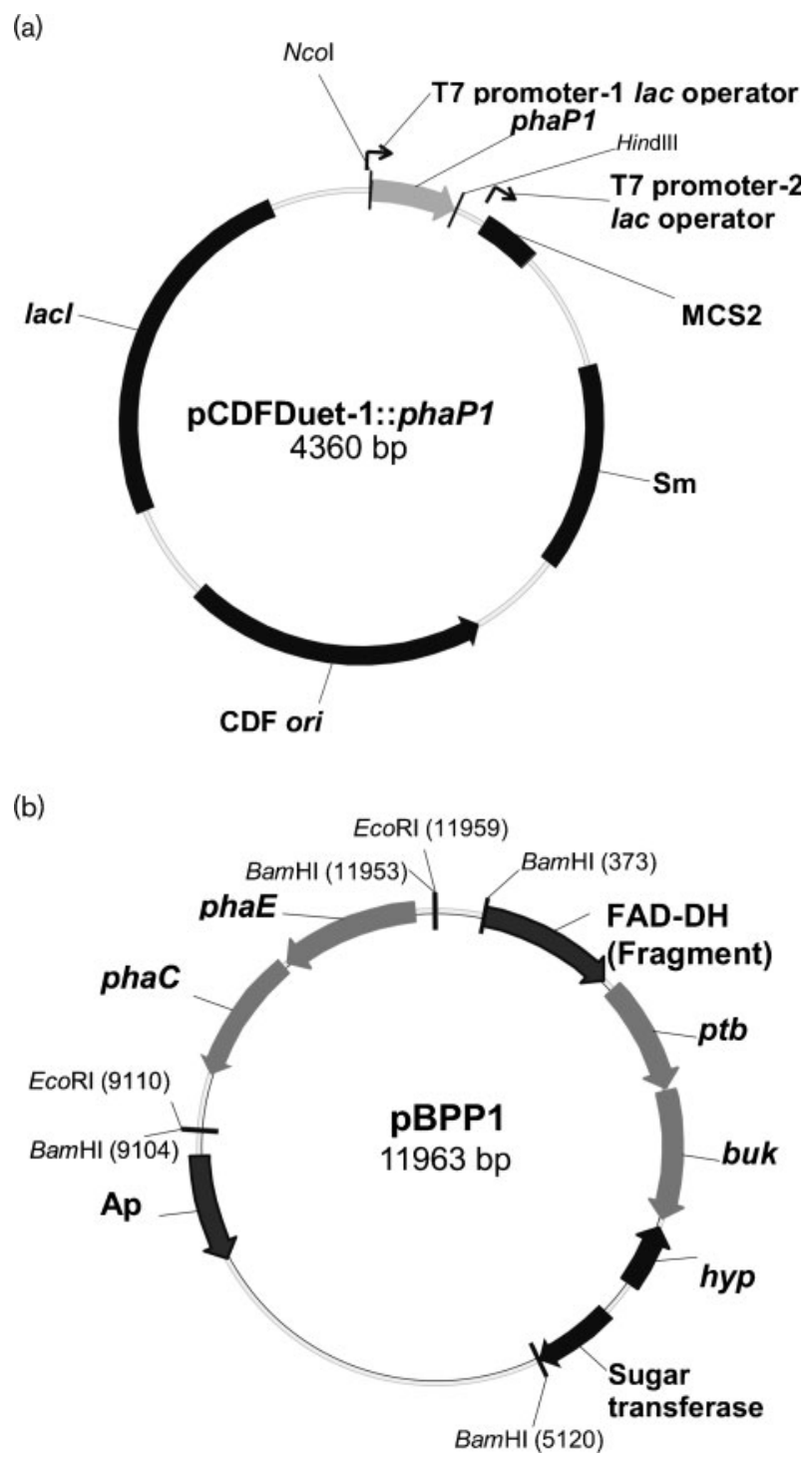

Fig. 1. Physical maps of plasmids pCDFDuet-1::phaP1 (a) and pBPP1 (b).

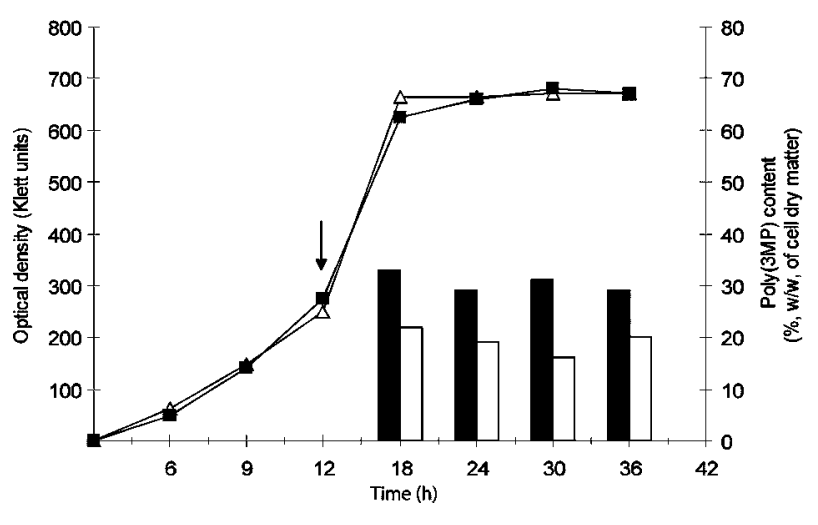

Fig. 2. Growth of $E$. coli BL21 (DE3)/pBPP1 and $E$. coli BL21 (DE3)/pBPP1+pCDFDuet-1::phaP1 in the presence of glucose plus 3-mercaptopropionic acid and accumulation of poly(3MP) in the cells. The composition of the medium and the cultivation conditions were as described in Methods. The arrow marks the time of IPTG $(1 \mathrm{mM})$ and $3 \mathrm{MP}(0.2 \%, \mathrm{v} / \mathrm{v})$ addition. After 18, 24, 30 and $36 \mathrm{~h}$, samples were withdrawn and poly(3MP) contents were analysed by GC. Squares and black bars represent growth behaviour and poly(3MP) content, respectively, of $E$. coli BL21 (DE3)/pBPP1+pCDFDuet$1:: p h a P 1$. Triangles and white bars represent growth behaviour and poly(3MP) content, respectively, of E. coli BL21 (DE3)/ pBPP1.

E. coli BL21 (DE3)/pBPP1+pCDFDuet-1::phaP1 cells, poly (3MP) contributed up to about $30 \%(\mathrm{w} / \mathrm{w})$ of the cell dry matter, whereas the poly(3MP) content of E. coli BL21 (DE3)/pBPP1 cells was only about $20 \%(\mathrm{w} / \mathrm{w})$ of the cell dry matter (Fig. 2). The situation was similar when the cells were cultivated in the presence of 3HB. Whereas E. coli BL21 (DE3)/pBPP1 + pCDFDuet-1::phaP1 cells accumulated poly $(3 \mathrm{HB})$ up to $27 \%(\mathrm{w} / \mathrm{w})$ of cell dry matter, this polymer amounted to only $17 \%(\mathrm{w} / \mathrm{w})$ of cell dry matter in E. coli BL21 (DE3)/pBPP1 cells (Fig. 3).

The results of these experiments clearly demonstrated that the major phasin PhaP1 of R. eutropha H16 exerts not only a positive effect on PHA accumulation in its own cells, but also if a PHA biosynthesis pathway is expressed in E. coli. The amounts of poly $(3 \mathrm{HB})$ synthesized by $R$. eutropha strains lacking intact PhaP by deletion of the gene or by Tn 5 insertion are decreased by about $50 \%$ compared to the wild-type (Wieczorek et al., 1995; York et al., 2002). It may be expected that similar positive effects also occur in other recombinant organisms expressing a PHA biosynthesis pathway. Moreover, this effect of $\mathrm{PhaP} 1$ is not restricted to biosynthesis and accumulation of polyoxoesters like poly $(3 \mathrm{HB})$, but also occurs with PTEs like poly (3MP) as clearly shown in this study. The positive effect of $\mathrm{PhaP} 1$ on polymer accumulation is significant, and the poly (3MP) and poly $(3 \mathrm{HB})$ contents of the cells could be increased by about 50 or $68 \%$, respectively. Both findings will be important for the optimization of strains suitable for biotechnological production of PHAs and PTEs. 


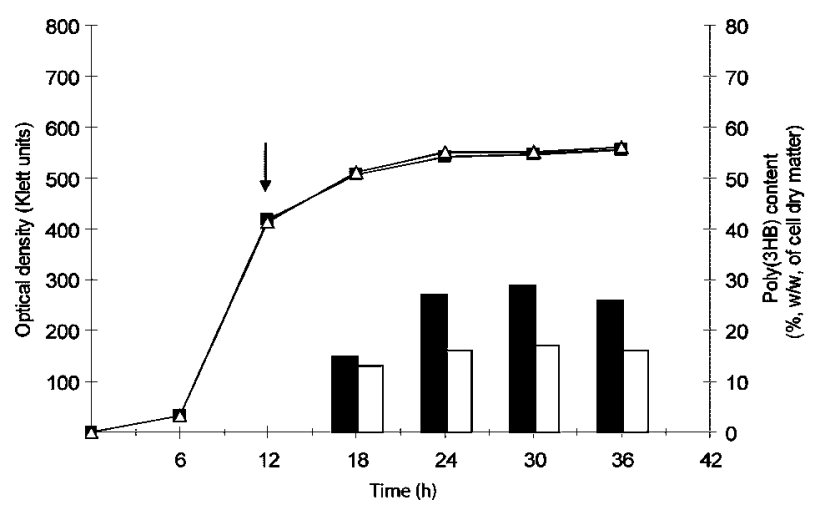

Fig. 3. Growth of $E$. coli BL21 (DE3)/pBPP1 and $E$. coli BL21 (DE3)/pBPP1 + pCDFDuet-1::phaP1 in the presence of glucose plus sodium 3-hydroxybutyrate and accumulation of poly $(3 \mathrm{HB})$ in the cells. The composition of the medium and the cultivation conditions were as described in Methods. The arrow marks the time of IPTG $(1 \mathrm{mM})$ and $3 \mathrm{HB}(0.2 \%, \mathrm{w} / \mathrm{v})$ addition. After 18, 24, 30 and $36 \mathrm{~h}$, samples were withdrawn and poly (3HB) contents were analysed by GC. Squares and black bars represent growth behaviour and poly(3HB) content, respectively, of $E$. coli BL21 (DE3)/pBPP1+pCDFDuet$1::$ phaP1. Triangles and white bars represent growth behaviour and poly(3HB) content, respectively, of E. coli BL21 (DE3)/ pBPP1.

These results are in line with other studies, in which a positive effect of phasins on PHA biosynthesis and accumulation was also observed. Studies with the purified PhaEC of Allochromatium vinosum have demonstrated that the amount of in vitro-synthesized poly $(3 \mathrm{HB})$ can be significantly increased by the addition of purified PhaP1 (Jossek et al., 1998). Studies with the purified PhaC2 of Pseudomonas aeruginosa have shown that PhaP1 from $R$. eutropha increases the activity of the PHA synthase by about 50\% (Qi et al., 2000). It is possible that PhaP1 has the same influence on the activity of the PHA synthase PhaEC during poly(3MP) accumulation. Experiments with a recombinant strain of $E$. coli harbouring a plasmid encoding the $p h b C A B$ operon have shown that the accumulation of poly $(3 \mathrm{HB})$ can be increased from about 16 to $57 \%$ of the cell dry matter when PhaP is also expressed (Seo et al., 2003). So far, unfortunately, a positive effect of phasins on PHA accumulation has not been demonstrated in transgenic plants. In transgenic Arabidopsis thaliana, coexpression of PhaP1 alongside PHB biosynthesis genes neither increases the polymer content nor alleviates the negative effect of expression of PHB biosynthesis on growth and development (Bohmert et al., 2002). To our knowledge, similar coexpression experiments have so far not been done in other transgenic plants.

\section{Analysis of poly(3HB) and poly(3MP) granule-associated proteins}

The protein patterns of crude extracts as well as those of isolated granules were analysed by PAGE in the same samples of E. coli BL21 (DE3)/pBPP1 and E. coli BL21 $(\mathrm{DE} 3) / \mathrm{pBPP} 1+\mathrm{pCDFDuet}-1:$ : phaP1 cells cultivated in the presence of $3 \mathrm{MP}$ or $3 \mathrm{HB}$ that were analysed for their polymer contents (see above). The expression of PhaP1 could be demonstrated in cells of E. coli BL21 (DE3)/ pBPP1+pCDFDuet-1::phaP1. The electropherograms of crude extracts of cells of $E$. coli BL21 (DE3)/ pBPP1 + pCDFDuet-1::phaP1, which were cultivated in the presence of $3 \mathrm{MP}$, showed abundant amounts of a protein with an apparent molecular mass of $22 \mathrm{kDa}$ representing PhaP1 (Fig. 4a). Similarly, crude extracts from cells of the same strain, which were cultivated in the presence of $3 \mathrm{HB}$, showed a protein of identical size (Fig. 5a). This protein band was absent in crude extracts prepared from cells of E. coli BL21 (DE3)/pBPP1. Surprisingly, however, a protein exhibiting an apparent molecular mass of about $16 \mathrm{kDa}$ occurred in the electropherograms of all crude extracts prepared from this E. coli strain which expressed the BPEC pathway but lacked phaP1, irrespective of whether the cells were cultivated in the presence of $3 \mathrm{MP}$ (Fig. 4a) or $3 \mathrm{HB}$ (Fig. 5a), respectively.

When the proteins from isolated poly $(3 \mathrm{MP})$ or poly $(3 \mathrm{HB})$ granules were separated by PAGE, either the phasin protein or the $16 \mathrm{kDa}$ protein occurred in the electropherograms depending on whether the granules were isolated from cells of E. coli BL21 (DE3)/pBPP1 + pCDFDuet-1 : : phaP1 or E. coli BL21 (DE3)/pBPP1 as shown in Figs 4(b) and 5(b), respectively. This demonstrated that, in the absence of phasin PhaP1, this $16 \mathrm{kDa}$ protein is expressed in E. coli and that it binds to the granules in the cytoplasm. MALDI-TOF analysis identified this $16 \mathrm{kDa}$ protein unequivocally as the small heat-shock protein HspA (accession no. NP_756468) of E. coli CFT073. HspA is identical with the small heatshock protein IbpA (accession no. P0C054) from E. coli. IbpA is expressed in $E$. coli in combination with another heat-shock protein, IbpB (accession no. P0C058), in situations where the cells are exposed to unfavourable conditions, for example during the overproduction of recombinant protein when it binds to inclusion bodies produced from recombinant proteins (Allen et al., 1992). The genes $i b p A$ and $i b p B$ constitute an operon, and the encoded proteins occur in complexes (Kuczyńska-Wiśnik et al., 2002). IbpB is stimulated by IbpA to associate with a substrate (Matuszewska et al., 2005). While expressing recombinant proteins, $E$. coli synthesizes large amounts of IbpA and IbpB, and the proteins are bound to the inclusion bodies (Han et al., 2004). Interestingly, expression of these proteins to a detectable level and binding to the granules did not occur in E. coli expressing PhaP1. Obviously, HspA seems to act like a phasin and binds to the PHA and PTE granules yielding increased amounts of either polymer in the cells. The electropherograms indicate that, irrespective of whether E. coli BL21 (DE3)/pBPP1 cells were cultivated in the presence of $3 \mathrm{MP}$ or $3 \mathrm{HB}$, they produce larger quantities of HspA than E. coli BL21 (DE3)/pBPP1+ pCDFDuet$1:$ :phaP1 cells produce PhaP1. Therefore, HspA is very abundant in the phasin-negative strains of $E$. coli. In recent 


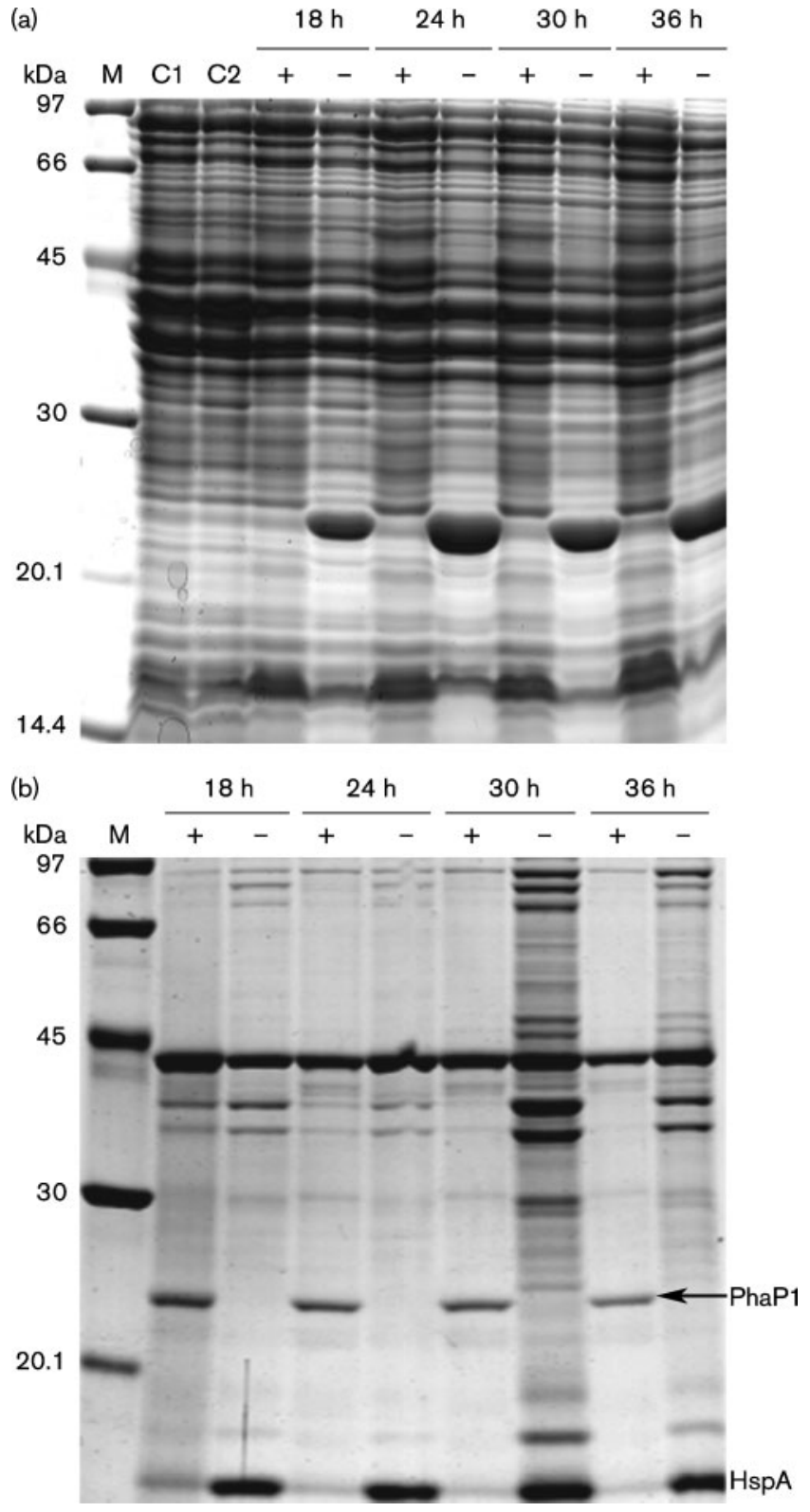

Fig. 4. Crude extracts (a) and isolated granules (b) of $E$. coli BL21 (DE3)/pBPP1 and E. coli BL21 (DE3)/ pBPP1 + pCDFDuet-1::phaP1 cultivated with glucose as carbon source and 3MP as precursor substrate. IPTG (1 mM) and 3MP $(0.2 \%, v / v)$ were added after $12 \mathrm{~h}$ of growth. Samples were taken before and after induction at different times. Proteins were separated in $12.5 \%(\mathrm{w} / \mathrm{v})$ SDS-polyacrylamide gels and stained with Coomassie brilliant blue. (a) Lanes: $\mathrm{C} 1$ and $\mathrm{C} 2$, negative controls of $E$. coli BL21 (DE3)/pBPP1 and $E$. coli BL21 (DE3)/ pBPP1 + pCDFDuet-1::phaP1, respectively, before induction of PhaP1; subsequent lanes, $E$. coli BL21 (DE3)/pBPP1 (-) and $E$. coli BL21 (DE3)/pBPP1 + pCDFDuet-1::phaP1 (+) withdrawn at the times indicated $(18,24,30$ or $36 \mathrm{~h}$, respectively). (b) Poly(3MP) granules from cells of $E$. coli BL21 (DE3)/pBPP1 (-) or E. coli BL21 (DE3)/pBPP1 + pCDFDuet-1 : : phaP1 (+) withdrawn at the times indicated $(18,24,30$ or $36 \mathrm{~h}$, respectively). studies, other larger heat-shock proteins, DnaK and GroEL/ ES, have been detected in R. eutropha as granule-associated proteins when phaP1 was deleted (Pötter et al., 2004). These heat-shock proteins were also found in recombinant E. coli expressing the phbCAB operon (Han et al., 2001).

\section{Electron microscopy studies}

It is assumed that phasins bind to PHA granules not only to stabilize the dispersion of the hydrophobic polymer in the hydrophilic cytoplasm, thereby preventing individual granules from coalescing to a few granules or even a single large granule as observed in a phaP1 mutant in $R$. eutropha (Wieczorek et al., 1995), but probably also to prevent the unspecific binding of other proteins to the large surface of the granules, thereby avoiding misrouting of proteins. This will protect the cells from various forms of stress. Previously, it was shown, surprisingly, that recombinant E. coli cells which accumulated poly(3MP), deposit the accumulated polymer in a large number of very small granules, although the cells lack a phasin (Lütke-Eversloh et al., 2002a; Lütke-Eversloh \& Steinbüchel, 2004). TEM images obtained in this study show that poly (3MP) granules isolated from E. coli BL21 (DE3)/pBPP1+pCDFDuet$1:$ : phaP1 were even smaller (Fig. $6 \mathrm{c}, \mathrm{d}$ ) than those isolated from cells of the phasin-negative strain (Fig. 6a, b). The mean size of the poly (3MP) granules was only $55 \pm 12 \mathrm{~nm}$ in cells of E. coli BL21 (DE3)/pBPP1 + pCDFDuet-1 : :phaP1 in comparison to the mean size of $105 \pm 12 \mathrm{~nm}$ in cells of $E$. coli BL21 (DE3)/pBPP1. Similarly, the mean size of poly $(3 \mathrm{HB})$ granules that accumulated in E. coli BL21 (DE3)/pBPP1 + pCDFDuet-1::phaP1 was $56 \pm 10 \mathrm{~nm}$ (Fig. 7a, b), whereas the mean size of the poly $(3 \mathrm{HB})$ granules in the phasin-negative strain was $110 \pm 22 \mathrm{~nm}$ (Fig. 7c, d). This indicates that HspA could act like a phasin and, due to the large amounts of this heat-shock protein, coalescence of individual granules is widely, although not completely, prevented in the absence of PhaP1. Mutants with a defect in HspA will probably accumulate much larger granules or even just one single granule if, instead of HspA, the formation of a further protein which compensates for the loss of HspA is not induced.

\section{Conclusions}

It was previously shown that proteins not related to PHA metabolism or PHA granule structure bind to the surface of PHA granules. Examples are lysozyme (Liebergesell \& Steinbüchel, 1992) and bovine serum albumin (Horowitz \& Sanders, 1995). Analysis of the PHA granule proteome by two-dimensional gel electrophoresis and MALDI-TOF analysis revealed the presence of homologues to the heatshock proteins DnaK and GroEL, and also the $\beta$ ketothiolase Bkt in PHA granules isolated from cells of a phasin-negative mutant of R. eutropha (Pötter et al., 2004). However, the latter proteins were not bound to the granules of the wild-type, thus indicating that their binding is prevented by the phasin. In a study by Han et al. (2001), it was shown that the expression of the heat-shock proteins 


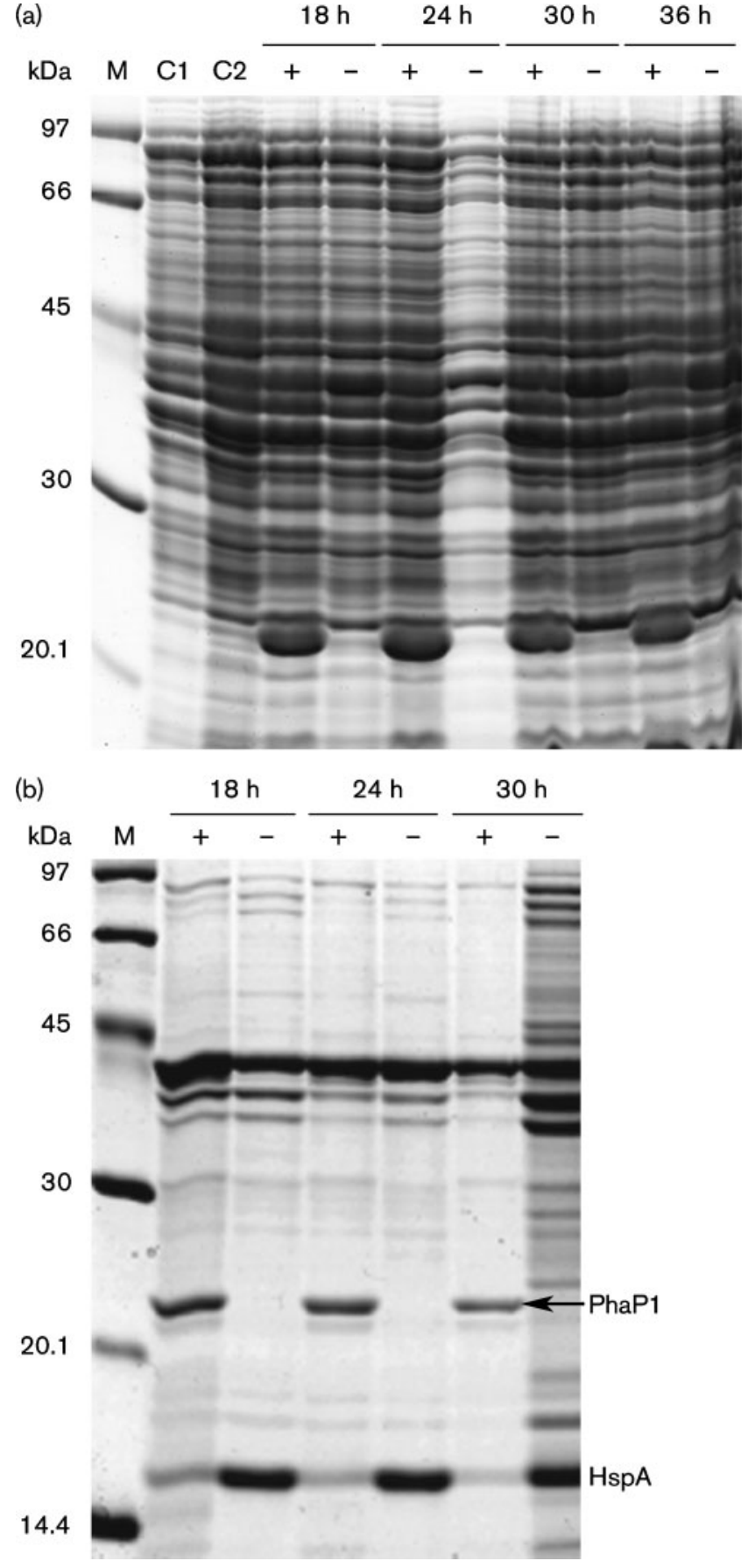

GroEL, GroES and DnaK was significantly up-regulated in a recombinant strain of E. coli expressing the Alcaligenes latus PHA biosynthesis genes; however, these proteins were detected only in crude extracts and no efforts were undertaken to analyse the PHA granule proteome in this E. coli strain. It has also been shown that the presence of these unspecifically bound proteins enhances the specific activity of the PHA synthase in vitro (Jossek et al., 1998). This and other studies indicate that the expression of PHA biosynthesis in $E$. coli causes stress to the cells and that significant changes occur in the proteome. E. coli synthesizes
Fig. 5. Crude extracts (a) and isolated granules (b) of E. coli BL21 (DE3)/pBPP1 and E. coli BL21 (DE3)/ pBPP1 + pCDFDuet-1::phaP1 cultivated with glucose as carbon source and $3 \mathrm{HB}$ as precursor substrate. IPTG (1 mM) and $3 \mathrm{HB}(0.2 \%, w / v)$ were added after $12 \mathrm{~h}$ of growth. Samples were taken before and after induction at different times. Proteins were separated in $12.5 \%$ (w/v) SDS-polyacrylamide gels and stained with Coomassie brilliant blue. (a) Lanes: $\mathrm{C} 1$ and $\mathrm{C} 2$, negative controls of $E$. coli BL21 (DE3)/pBPP1 and E. coli BL21 (DE3)/pBPP1 + pCDFDuet-1 : : phaP1, respectively, before induction of PhaP1; subsequent lanes, E. coli BL21 (DE3)/pBPP1 (-) and E. coli BL21 (DE3)/pBPP1 + pCDFDuet$1::$ phaP1 (+) withdrawn at the times indicated $(18,24,30$ or $36 \mathrm{~h}$, respectively). (b) Poly(3HB) granules from cells of $E$. coli BL21 (DE3)/pBPP1 (-) and E. coli BL21 (DE3)/ pBPP1 + pCDFDuet-1::phaP1 (+) withdrawn at the times indicated in the figure $(18,24$ or $30 \mathrm{~h}$, respectively).

small heat-shock proteins to reduce stress by binding these proteins to recombinant expressed inclusion bodies. However, the influence of $\mathrm{HspA}$ is not equal to the influence of PhaP1 on poly $(3 \mathrm{HB})$ accumulation in $R$. eutropha H16, which can be observed in the different amounts of accumulated polymer. Because of the physical properties of PTEs and with regard to their industrial use, for example in medical or technical applications, these
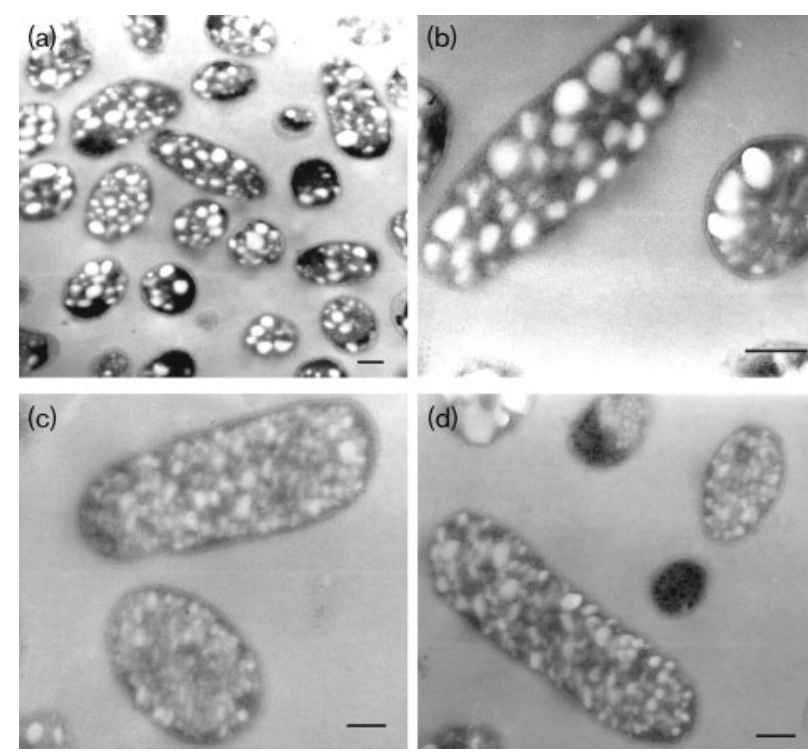

Fig. 6. TEM of poly(3MP)-accumulating cells of recombinant strains of $E$. coli BL21 (DE3) expressing the BPEC pathway in the absence or presence of PhaP1. E. coli BL21 (DE3)/pBPP1 cells are shown in (a) and (b), whereas E. coli BL21 (DE3)/ pBPP1 + pCDFDuet-1::phaP1 cells are shown in (c) and (d). Cells were cultivated in M9 medium containing $1 \%$ glucose $(\mathrm{w} / \mathrm{v})$ plus $0.2 \% 3 \mathrm{MP}(\mathrm{v} / \mathrm{v})$ and were harvested in the stationary phase after $24 \mathrm{~h}$ growth. Thin sections were prepared and electron micrographs were obtained as described in Methods. Bars, $0.2 \mu \mathrm{m}$. 




Fig. 7. TEM of poly(3HB)-accumulating cells of recombinant strains of $E$. coli BL21 (DE3) expressing the BPEC pathway in the absence or presence of PhaP1 after cultivation in the presence of glucose and 3HB. E. coli BL21 (DE3)/pBPP1 cells are shown in (a) and (b), whereas $E$. coli BL21 (DE3)/ pBPP1 + pCDFDuet-1::phaP1 cells are shown in (c) and (d). Cells were cultivated in M9 medium containing $1 \%$ glucose $(\mathrm{w} / \mathrm{v})$ plus $0.2 \% 3 \mathrm{HB}(\mathrm{w} / \mathrm{v})$ and were harvested in the stationary phase after $24 \mathrm{~h}$ growth. Thin sections were prepared and electron micrographs were obtained as described in Methods. Bars, $0.2 \mu \mathrm{m}$.

findings will be important for optimization of the biotechnological production of PTEs.

\section{ACKNOWLEDGEMENTS}

This study was supported by a grant provided by the Deutsche Forschungsgemeinschaft (DFG) to A.S. (Ste 386/6-4).

\section{REFERENCES}

Allen, S. P., Polyzzi, J. O., Gierse, J. K. \& Easton, A. M. (1992). Two novel heat shock genes encoding proteins produced in response to heterologous protein expression in Escherichia coli. J Bacteriol 174, 6938-6947.

Bohmert, K., Balbo, I., Steinbüchel, A., Tischendorf, G. \& Willmitzer, L. (2002). Constitutive expression of the $\beta$-ketothiolase gene in transgenic plants. A major obstacle for obtaining polyhydroxybutyrate-producing plants. Plant Physiol 128, 1282-1290.

Brandl, H., Gross, R. A., Lenz, R. W. \& Fuller, R. C. (1988). Pseudomonas oleovorans as a source of poly ( $\beta$-hydroxyalkanoates) for potential applications as biodegradable polyesters. Appl Environ Microbiol 66, 2117-2124.

Elbanna, K., Lütke-Eversloh, T., Jendrossek, D., Luftmann, H. \& Steinbüchel, A. (2004). Studies on the biodegradability of polythioester copolymers and homopolymers by polyhydroxyalkanoate (PHA)-degrading bacteria and PHA depolymerases. Arch Microbiol 182, 212-225.

Han, M.-J., Yoon, S. S. \& Lee, S. Y. (2001). Proteome analysis of metabolically engineered Escherichia coli producing poly(3-hydroxybutyrate). J Bacteriol 183, 301-308.

Han, M.-J., Park, S. J., Park, T. J. \& Lee, S. Y. (2004). Roles and applications of small heat shock proteins in the production of recombinant proteins in Escherichia coli. Biotechnol Bioeng 88, 426-436.

Hanahan, D. (1983). Studies on transformation of Escherichia coli with plasmids. J Mol Biol 166, 557-580.

Horowitz, D. M. \& Sanders, J. K. M. (1995). Biomimetic, amorphous granules of polyhydroxybutyrate: composition, mobility, and stabilization in vitro by proteins. Can J Microbiol 41 (Suppl. 1), 115-123.

Iwata, S., Thoshima, S. \& Matsumara, S. (2003). Enzyme-catalyzed preparation of aliphatic polyesters containing thioester linkages. Macromol Rapid Commun 24, 467-471.

Jossek, R., Reichelt, R. \& Steinbüchel, A. (1998). In vitro biosynthesis of poly(3-hydroxybutyric acid) by using purified poly(hydroxyalkanoic acid) synthase of Chromatium vinosum. Appl Microbiol Biotechnol 49, 258-266.

Kato, M., Toshima, K. \& Matsumura, S. (2005). Preparation of aliphatic poly(thioester) by the lipase-catalyzed direct polycondensation of 11mercaptoundecanoic acid. Biomacromolecules 6, 2275-2280.

Kawada, J., Lütke-Eversloh, T., Steinbüchel, A. \& Marchessault, R. H. (2003). Physical properties of microbial polythioesters: characterization of poly(3-mercaptoalkanoates) synthesized by engineered Escherichia coli. Biomacromolecules 4, 1698-1702.

Kim, D. Y., Lütke-Eversloh, T., Elbanna, K., Thakor, N. \& Steinbüchel, A. (2005). Poly(3-mercaptopropionate): a nonbiodegradable biopolymer? Biomacromolecules 6, 897-901.

Koltzscher, M., Neumann, C., König, S. \& Gerke, V. (2003). A novel approach in search for dimer-specific S100 protein ligands identifies ezrin as a binding partner for S100P: $\mathrm{Ca}^{2+}$ activation by dormant ezrin by S100P. Mol Biol Cell 14, 2372-2384.

Kuczyńska-Wiśnik, D., Kedzierska, S., Matuszewska, E., Lund, P., Taylor, A., Lipinska, B. \& Laskowska, E. (2002). Transcription of the $i b p B$ heat shock gene is under control of sigma(32)- and sigma(54)promoters, a third regulon of heat shock response. Biochem Biophys Res Commun 284, 57-64.

Laemmli, U. K. (1970). Cleavage of structural proteins during the assembly of the head of bacteriophage T4. Nature 227, 680-685.

Liebergesell, M. \& Steinbüchel, A. (1992). Isolation and identification of granule-associated proteins relevant for poly(3-hydroxyalkanoic acid) biosynthesis in Chromatium vinosum D. FEMS Microbiol Lett 99, 227-232.

Liu, S. J. \& Steinbüchel, A. (2000a). Exploitation of butyrate kinase and phosphotrans-butyrylase from Clostridium acetobutylicum for the in vitro biosynthesis of poly(hydroxyalkanoic acid). Appl Microbiol Biotechnol 53, 545-552.

Liu, S. J. \& Steinbüchel, A. (2000b). A novel genetically engineered pathway for synthesis of poly(hydroxyalkanoic acids) in Escherichia coli. Appl Environ Microbiol 66, 739-743.

Lütke-Eversloh, T. \& Steinbüchel, A. (2003). Novel precursor substrates for polythioesters (PTE) and limits of PTE synthesis in Ralstonia eutropha. FEMS Microbiol Lett 221, 191-196.

Lütke-Eversloh, T. \& Steinbüchel, A. (2004). Microbial polythioesters. Macromol Biosci 4, 165-174.

Lütke-Eversloh, T., Bergander, K., Luftmann, H. \& Steinbüchel, A. (2001a). Identification of a new class of biopolymer: bacterial 
synthesis of a sulfur-containing polymer with thioester linkages. Microbiology 147, 11-19.

Lütke-Eversloh, T., Bergander, K., Luftmann, H. \& Steinbüchel, A. (2001b). Biosynthesis of poly(3-hydroxybutyrate-co-3-mercaptobutyrate) as a sulfur analogue to poly(3-hydroxybutyrate) (PHB). Biomacromolecules 2, 1061-1065.

Lütke-Eversloh, T., Fischer, A., Remminghorst, U., Kawada, J., Marchessault, R. H., Bögershausen, A., Kalwei, M., Eckert, H. \& other authors (2002a). Biosynthesis of novel thermoplastic polythioesters by engineered Escherichia coli. Nat Mater 1, 236-240.

Lütke-Eversloh, T., Kawada, J., Marchessault, H. \& Steinbüchel, A. (2002b). Characterization of microbial polythioesters: physical properties of novel copolymers synthesized by Ralstonia eutropha. Biomacromolecules 3, 159-166.

Matuszewska, M., Kuczyńska-Wiśnik, D., Laskowska, E. \& Liberek, K. (2005). The small heat shock protein IbpA of Escherichia coli cooperates with $\mathrm{IbpB}$ in stabilization of thermally aggregated proteins in a disaggregation competent state. J Biol Chem 280, 12292-12298.

Pötter, M. \& Steinbüchel, A. (2005). Poly(3-hydroxybutyrate) granule-associated proteins: impacts on poly(3-hydroxybutyrate) synthesis and degradation. Biomacromolecules 6, 552-560.

Pötter, M., Müller, H., Reinecke, F., Wieczorek, R., Fricke, F., Bowien, B., Friedrich, B. \& Steinbüchel, A. (2004). The complex structure of polyhydroxybutyrate (PHB) granules: four orthologous and paralogous phasins occur in Ralstonia eutropha. Microbiology 150, 2301-2311.

Preusting, H., Kingma, J., Huisman, G., Steinbüchel, A. \& Witholt, B. (1993). Formation of polyester blends by a recombinant strain of Pseudomonas oleovorans: different poly(3-hydroxyalkanoates) are stored in separate granules. J Environ Polym Degrad 1, 11-21.

Qi, Q., Steinbüchel, A. \& Rehm, B. H. A. (2000). In vitro synthesis of poly(3-hydroxydecanoate): purification of type II polyhydroxyalkanoate synthases $\mathrm{PhaC} 1$ and $\mathrm{PhaC} 2$ from Pseudomonas aeruginosa and development of an enzyme assay. Appl Microbiol Biotechnol 54, $37-43$.

Sambrook, J., Fritsch, E. F. \& Maniatis, T. (1989). Molecular Cloning: a Laboratory Manual, 2nd edn. Cold Spring Harbor, NY: Cold Spring Harbor Laboratory.

Seo, M.-C., Shin, H.-D. \& Lee, Y.-H. (2003). Functional role of granule-associated genes, $p h a P$ and $p h a R$, in poly- $\beta$-hydroxybutyrate biosynthesis in recombinant $E$. coli harbouring $p h b C A B$ operon. Biotechnol Lett 25, 1243-1249.

Spurr, A. R. (1969). A low-viscosity epoxy resin embedding medium for electron microscopy. J Ultrastruct Res 26, 31-43.

Steinbüchel, A. \& Valentin, H. E. (1995). Diversity of bacterial polyhydroxyalkanoic acids. FEMS Microbiol Lett 128, 219-228.

Steinbüchel, A., Aerts, K., Babel, W., Follner, C., Liebergesell, M., Madkour, M. H., Mayer, F., Pieper-Fürst, U. \& other authors (1995). Considerations on the structure and biochemistry of bacterial polyhydroxyalkanoic acid inclusions. Can J Microbiol 41 (Suppl. 1), 94-105.

Taguchi, S. \& Doi, Y. (2004). Evolution of polyhydroxyalkanoate (PHA) production system by 'enzyme evolution': successful case studies of directed evolution. Macromol Biosci 4, 146-156.

Tanaka, M., Takebayashi, M., Miyama, M., Nishada, J. \& Shimomura, M. (2004). Design of novel biointerfaces (II). Fabrication of self-organized porous polymer film with highly uniform pores. Biomed Mater Eng 14, 439-446.

Thakor, N., Lütke-Eversloh, T. \& Steinbüchel, A. (2005). Application of the BPEC pathway for large-scale biotechnological production of poly(3-mercaptopropionate) by recombinant Escherichia coli, including a novel in situ isolation method. Appl Environ Microbiol 71, 835-841.

Timm, A. \& Steinbüchel, A. (1990). Formation of polyesters consisting of medium-chain-length 3-hydroxyalkanoic acids from gluconate by Pseudomonas aeruginosa and other fluorescent pseudomonads. Appl Environ Microbiol 56, 3360-3367.

Weber, K. \& Osborn, M. (1969). The reliability of molecular weight determinations by dodecyl sulfate-polyacrylamide gel electrophoresis. J Biol Chem 244, 4406-4412.

Wieczorek, R., Pries, A., Steinbüchel, A. \& Mayer, F. (1995). Analysis of a 24-kilodalton protein associated with the polyhydroxyalkanoic acid granules in Alcaligenes eutrophus. J Bacteriol 177, 2425-2435.

York, G. M., Stubbe, J. \& Sinskey, A. J. (2002). The Ralstonia eutropha PhaR protein couples synthesis of the PhaP phasin to the presence of polyhydroxybutyrate in cells and promotes polyhydroxybutyrate production. J Bacteriol 184, 59-66.

Edited by: M. Hecker 